\title{
COMMENT
}

\section{August 2019 ECI biocommentary}

\author{
Melissa Smarr (D) \\ Pediatric Research (2019) 86:144; https://doi.org/10.1038/s41390-019-0441-5
}

Moving from Pittsburgh, Pennsylvania to Roanoke Rapids, North Carolina during early childhood was an eye-opening experience. Spending my early childhood in neighborhoods within close proximity to polluting industries and major roadways did not seem abnormal or worrisome until my family moved to suburban communities with lots of greenspace in the rural south. I quickly came to realize the disparities in exposures to environmental hazards and the vulnerability of many population sub-groups. These early childhood experiences influenced my desire to better understand differences in environmental exposures and cardiovascular outcomes between non-Hispanic White and non-Hispanic Black populations. However, it was during my doctoral program at the University of Michigan, School of Public Health that my mentor, Dr. Marie O'Neill, helped me to recognize that pregnant women and their unborn fetuses are among those vulnerable to environmental effects. Working on an international multidisciplinary project studying prenatal exposures to air pollution and fetal growth in Mexico City, Mexico, alerted me to global public health concerns of environmental health. Under the guidance of my postdoctoral mentors, Drs. Germaine Buck Louis (Reproductive Toxicologist) and Katherine Grantz (Maternal-Fetal Medicine), at the Eunice Kennedy Shriver National Institute of Child Health and Development, I became passionate about investigating modifiable environmental exposures in the area of perinatal and pediatric research. Currently, as an Assistant Professor in the Department of Environmental Health at the Rollins School of Public Health, Emory University, I am able to continue to pursue my passion for pediatric research and am fortunate to collaborate with numerous interdisciplinary research teams on research projects designed to investigate the role of environmental exposures on perinatal and pediatric health outcomes. Specifically, I am excited to have opportunities to learn more about maternal and early childhood environmental exposures among African-Americans in the Metropolitan Atlanta area and Asians in the Chiang Mai Province of Thailand. The totality of these lived experiences has shaped my research interests and career as a Reproductive and Environmental Epidemiologist. My advice to those starting out in the field is to be open-minded and willing to explore new directions. Always strive to challenge yourself and be willing to accept the challenges presented by trustworthy mentors.

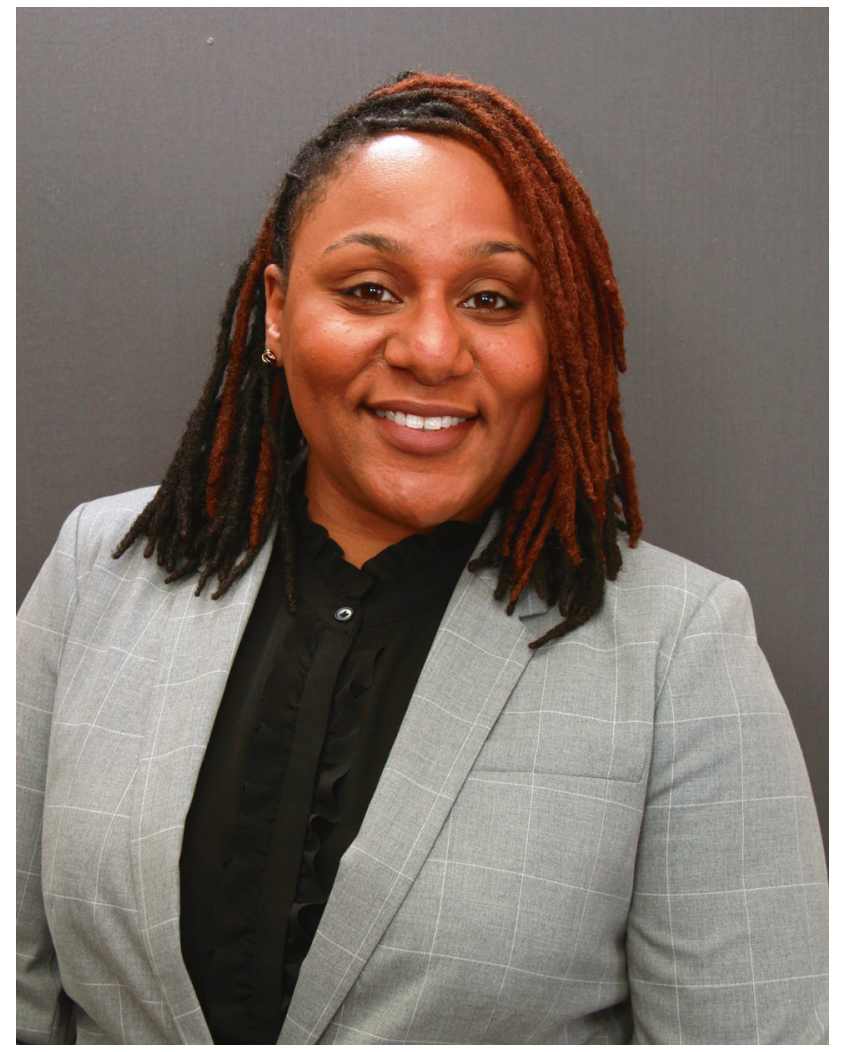

\section{ADDITIONAL INFORMATION}

Competing interests: The author declares no competing interests.

Publisher's note: Springer Nature remains neutral with regard to jurisdictional claims in published maps and institutional affiliations.

${ }^{1}$ Emory University School of Public Health Atlanta GA, 1518 Clifton Road, NE Mailstop 1518-002-2BB, Atlanta, GA 30322, USA

Correspondence: Melissa Smarr (melissa.smarr@emory.edu)

Received: 22 April 2019 Accepted: 18 May 2019

Published online: 27 May 2019 